OPEN ACCESS

Edited by:

Ben Nephew,

Worcester Polytechnic Institute,

United States

Reviewed by:

Archana Hinduja,

The Ohio State University,

United States

Thiago Cardoso Vale,

Juiz de Fora Federal University, Brazil

*Correspondence:

Weiyu Teng

tengweiyucmu@sina.com

Li Tian

tianli_cmu2@126.com

tThese authors have contributed equally to this work

Specialty section: This article was submitted to Neuroendocrine Science, a section of the journal

Frontiers in Neuroscience

Received: 04 April 2021

Accepted: 11 May 2021

Published: 23 June 2021

Citation:

Dong M, E J-Y, Zhang L, Teng $W$ and

Tian L (2021) Non-ketotic

Hyperglycemia Chorea-Ballismus and Intracerebral Hemorrhage: A Case

Report and Literature Review.

Front. Neurosci. 15:690761. doi: 10.3389/fnins.2021.690761

\section{Non-ketotic Hyperglycemia Chorea-Ballismus and Intracerebral Hemorrhage: A Case Report and Literature Review}

\author{
Mingming Dong ${ }^{1,2}$, Jian-Yu $E^{3}$, Liyang Zhang ${ }^{1}$, Weiyu Teng ${ }^{2 * t}$ and Li Tian ${ }^{4 * t}$ \\ ${ }^{1}$ Department of Neurology, The Fourth People's Hospital of Shenyang, Shenyang, China, ${ }^{2}$ Department of Neurology, The First \\ Hospital of China Medical University, Shenyang, China, ${ }^{3}$ Wilmer Eye Institute, Johns Hopkins University School of Medicine, \\ Baltimore, MD, United States, ${ }^{4}$ Department of Geriatrics, Shengjing Hospital of China Medical University, Shenyang, China
}

Non-ketotic hyperglycemia chorea-ballismus (NKH-CB) is a rare metabolical syndrome secondary to the hyperglycemic condition, which is characterized by a triad of acute or subacute hemichorea-hemiballismus, hyperglycemic state, and unique abnormalities limited to the striatum on neuroimaging. Several related case studies on this disorder have been reported previously, but NKH-CB had never been associated with intracerebral hemorrhage $(\mathrm{ICH})$. Herein, we report an uncommon case of $\mathrm{NKH}-\mathrm{CB}$ and $\mathrm{ICH}$ that occurred simultaneously in one patient, which provides a challenge for clinicians in making a correct diagnosis. An 88-year-old woman with a long-term history of poor-controlled type 2 diabetes mellitus and hypertension, who presented with a suddenonset headache, restlessness, severe bilateral choreiform and ballistic movements, elevated levels of glucose and osmolality in the serum, an increased white blood cell count, and two-type hyperdense signs on CT imaging, was finally diagnosed with $\mathrm{NKH}-\mathrm{CB}$ and $\mathrm{ICH}$. Despite administrated active treatments, the patient's clinical status did not improve and ultimately passed away. This case is reported to remind clinicians to consider the possibility of NKH-CB when patients present sudden-onset choreiform and ballistic movements. It is also the first entity with two-type hyperdense signs on CT imaging simultaneously, which helps us distinguish $\mathrm{NKH}-\mathrm{CB}$ from $\mathrm{ICH}$ more intuitively.

Keywords: non-ketotic hyperglycemia chorea-ballismus, diabetic striatopathy, intracerebral hemorrhage, case report, metabolical syndrome, hyperdense signs on neuroimaging, differential diagnosis

\section{INTRODUCTION}

Non-ketotic hyperglycemia chorea-ballismus (NKH-CB) is a rare metabolical syndrome secondary to the hyperglycemic condition. The classic clinical manifestation of this disorder includes a triad of acute or subacute hemichorea-hemiballismus, hyperglycemic state, and unique reversible abnormalities limited to the striatum on neuroimaging (Wintermark et al., 2004). Because of unfamiliarity and radiographic features easily misdiagnosed as intracerebral hemorrhage (ICH) for most physicians, the prevalence of NKH-CB is believed to be underestimated with the rate of $\sim 1$ in 100,000 (Ondo, 2011). This disorder has been reported to occur predominantly in elderly Asian women with type 2 diabetes mellitus and generally has a favorable prognosis 
after correcting hyperglycemia. Currently, several related case studies on this disorder have been reported previously, but $\mathrm{NKH}-\mathrm{CB}$ had never been associated with ICH. Herein, we describe an uncommon case of NKH-CB and $\mathrm{ICH}$ that occurred simultaneously in one patient, which provides a challenge for clinicians in making a correct diagnosis. Despite administrated active treatments, the patient's clinical status did not improve and ultimately died. We report this case to remind clinicians to be familiar with and to recognize early this unusual disorder. We also discuss potential mechanisms that lead to a poor prognosis of our case.

\section{CASE REPORT}

An 88-year-old woman with a long-term history of poorcontrolled type 2 diabetes mellitus and hypertension was admitted to the emergency department for sudden onset of headache, restlessness, and severe involuntary movements of the four limbs for 1 day. During transit to our hospital, she became speech confused after vomiting blood. The patient's family denied that she had family history, drug and toxic exposure, which led to abnormal movement.

The patient had no fever and normal vital signs except for blood pressure 184/98 mmHg. On examination, she was restless, nonsense, confused, and unable to converse correctly. Bilateral pupils were normal and reactive to light with no Kayser-Fleischer ring. She presented with remarkable bilateral choreiform and ballistic movements of the limbs, which were more severe in the upper limbs (continuous, irregular, and involuntary jerking movements) with hypotonia and normal muscle strength. The tendon reflex, neck resistance, and Babinski sign were negative. She could not cooperate with the remaining examinations (other cranial nerves, sensation, coordination, and gait).

Laboratory results on the emergency (Table 1, first day) were clinically significant for leukocytosis, neutrophilia, elevated C-reactive protein, hyperglycemia, elevated serum osmolality, positive urine sugar, negative urine ketone, and hypoxemia. A non-contrast brain computed tomography (CT) showed hyperdensity in the left occipital lobe with a mean CT attenuation value of 72 Hounsfield unit (HU) and bilateral striatal regions (right caudate nucleus and putamen with a mean value of $49 \mathrm{HU}$, left caudate nucleus with a mean value of $43 \mathrm{HU}$ ) (Figures 1A,B).

The emergency physicians considered those lesions as acute $\mathrm{ICH}$ for the first time, and the patient was then admitted to our neurology department. A contrasted brain CT at $8 \mathrm{~h}$ later of hospitalization, however, disclosed the over-time evolution differences in these lesions: slightly increased edema around the occipital lobe lesion with mild hematoma enlargement (a mean value of $75 \mathrm{HU}$ ), whereas no significant changes in the striatal regions were observed (still regular, well-defined, limited without edema, and mass effect; a mean value of $51 \mathrm{HU}$ and $44 \mathrm{HU}$ in the right and left side, respectively), reassuring that the striatum lesions were not hemorrhagic damage (Figures 1C,D). Supplemental laboratory examinations including thyroid and parathyroid function, serum electrolyte levels, coagulation profile, autoimmune antibodies, liver and
TABLE 1 | Laboratory investigations on admission (first day) and sixth day in hospital.

\begin{tabular}{|c|c|c|c|}
\hline \multirow[t]{2}{*}{ Investigation } & \multicolumn{2}{|c|}{ Result } & \multirow[t]{2}{*}{ Reference range } \\
\hline & First day & Sixth day & \\
\hline White blood cell count, $\times 10^{9} / \mathrm{L}$ & 10.04 & 14.21 & $3.5-9.5$ \\
\hline Absolute neutrophil count, $\times 10^{9} / \mathrm{L}$ & 9.07 & 13.15 & $1.8-6.3$ \\
\hline Absolute lymphocyte count, $\times 10^{9} / \mathrm{L}$ & 1.2 & 0.5 & $1.1-3.2$ \\
\hline C-reactive protein, mg/L & 4.34 & 179.73 & $0.1-10.0$ \\
\hline Serum glucose, mg/dl & 300.6 & 599.4 & $70.2-109.8$ \\
\hline Hemoglobin A1c, \% & 15.2 & NA & $3.8-6.5$ \\
\hline Urea nitrogen, mmol/L & 6.66 & 27.45 & $3.1-8.8$ \\
\hline Creatinine, $\mu \mathrm{mol} / \mathrm{L}$ & 44 & 187 & $41-81$ \\
\hline Sodium, mmol/L & 141 & 133 & $137-147$ \\
\hline Potassium, mmol/L & 4.5 & 4.57 & $3.50-5.30$ \\
\hline Serum osmolality, mOsm/kg & 314.36 & 335.89 & 280-310 \\
\hline \multicolumn{4}{|l|}{ Arterial blood gas } \\
\hline $\mathrm{pH}$ & 7.333 & NA & $7.350-7.450$ \\
\hline $\mathrm{PaO}_{2}, \mathrm{mmHg}$ & 57.5 & NA & $83.0-108.0$ \\
\hline $\mathrm{PaCO}_{2}, \mathrm{mmHg}$ & 23.7 & NA & $32.0-48.0$ \\
\hline $\mathrm{HCO}_{3}^{-}, \mathrm{mmol} / \mathrm{L}$ & 15.5 & NA & $22.0-27.8$ \\
\hline Urine glucose & $4+$ & NA & - \\
\hline Urine ketone & - & NA & - \\
\hline
\end{tabular}

NA, not applicable.

kidney function, ceruloplasmin, vitamins D and B12, folic acid, human immunodeficiency virus antibody, syphilis antibody, erythrocyte sedimentation rate, anti-O antibody, and serum cancer markers were normal. The chest X-ray indicated inflammation in the upper-lobe segment of the left lung. Based on these clinical data and excluding the possibility of other diseases, the patient was ultimately diagnosed with $\mathrm{NKH}-\mathrm{CB}$ and ICH. The secondary diagnoses included stressrelated upper gastrointestinal bleeding, aspiration pneumonia, and hypertension. A chart review of her 15-day-ago records with a CT image of hyperdensity in bilateral striatum (a mean value of $46 \mathrm{HU}$ and $43 \mathrm{HU}$ in the right and left side, respectively) without edema, mass effect, and occipital lobe lesion (Figures 1E,F) further confirmed our diagnosis. At that time, the patient only complained of mild dizziness for 3 days; however, no subsequent investigations were conducted because the then clinician paid insufficient attention to these abnormal neuroimaging findings, as well as considered that the symptom of the patient was mild.

The patient received supportive management, including the use of a cardiac monitor, oxygen, anti-hyperglycemic therapy with fluids and insulin, as well as a series of symptomatic treatments, including controlling choreiform and ballistic movements with clonazepam (1 mg per night), antihypertensive, anti-inflammatory, and acid suppression therapy. On the third day, with the reduction of hyperglycemia (blood glucose was controlled at $163.8-189 \mathrm{mg} / \mathrm{dl}$ ), the symptoms of chorea-ballismus and confusion improved, and the patient could converse briefly. The patient denied any visual symptoms such as blurred and distorted vision. Three days later, the 


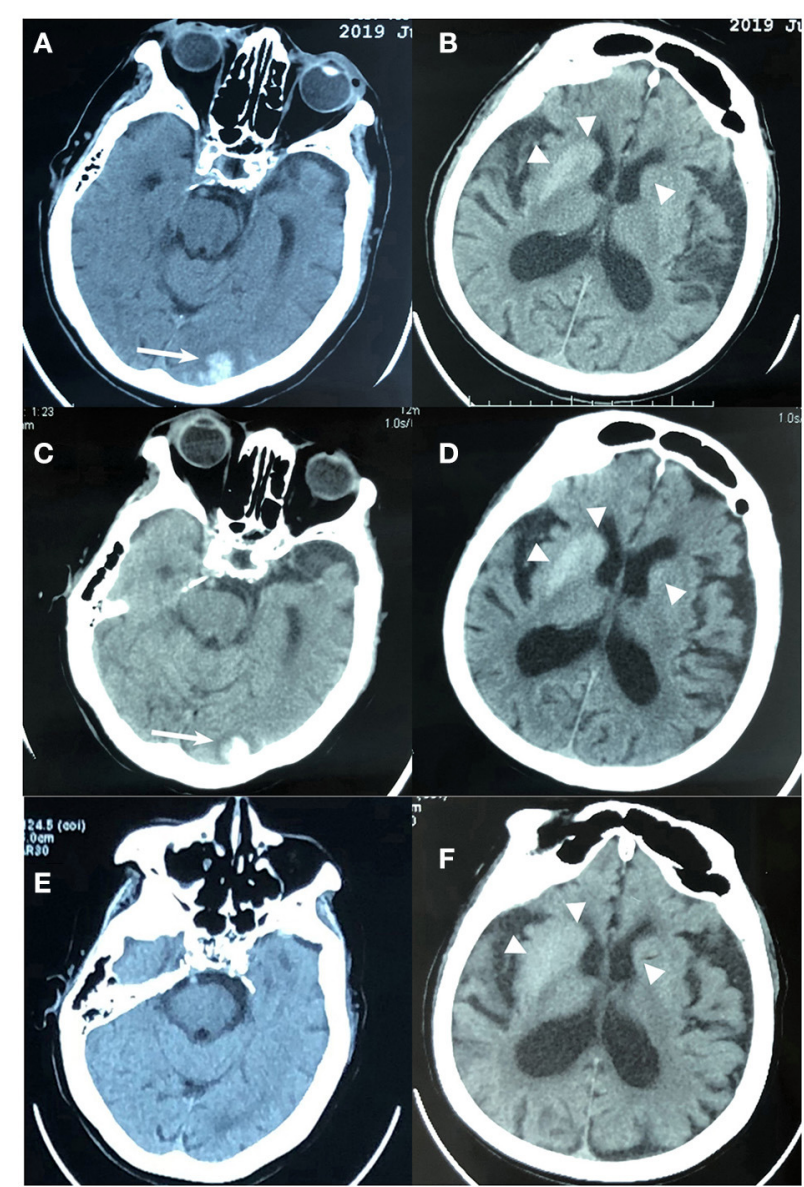

FIGURE 1 | Brain computed tomography (CT) imaging of an 88-year-old woman with non-ketotic hyperglycemia chorea-ballism and intracerebral hemorrhage. (A,B) At admission, CT showed hyperdense lesions in the left occipital lobe (white arrow), right caudate nucleus and putamen (triangle), and left caudate (triangle). (C,D) Eight hours later after admission, CT showed mild hematoma enlargement, slightly increased edema around the occipital lobe lesion (white arrow), and no significant changes in the bilateral striatum regions (triangle); (E,F) 15 days before admission, CT showed hyperdensity in bilateral striatum regions (triangle) without edema and occipital lobe lesion.

patient had a fever $\left(38.0^{\circ} \mathrm{C}\right)$ with the laboratory results worsening (Table 1, sixth day), and her condition deteriorated rapidly to coma without chorea-ballismus movements due to severe uncontrolled infection and recurrent hyperglycemic crisis. Despite administrated intensive treatments, including fluid resuscitation, glycemic control, and anti-inflammation, the patient's clinical status did not improve and her relatives decided to suspend treatments due to limited financial support. On day 8 , unfortunately, the patient developed digestive tract rebleeding and ultimately passed away.

\section{DISCUSSION}

$\mathrm{KH}-\mathrm{CB}$, also recognized as diabetic striatopathy, is a rare complication of diabetes mellitus (Xiao et al., 2019) and was first described by Bedwell (1960). Chua et al. (2020) found that NKHCB frequently occurs in Asia (71.6\% in total reported cases), particularly the older women with new-onset or uncontrolled diabetes, with an average onset age of 67.6 years old, and the sex ratio (male to female) was 1:1.7. Among the numerous causes of chorea-ballismus, non-ketotic hyperglycemia is the most common in the metabolic cause group, but it is still scarce with roughly $1 \%$ of the total etiologies in a recent study by Mayo Clinic (Ryan et al., 2018). Besides, the chorea-ballismus movement can also be observed in some ketotic diabetic patients, adolescents with newly diagnosed diabetes, and even children (Tan Y. et al., 2014; Aquino et al., 2015; Faundez et al., 2016). Other causes that could induce acute/subacute-onset choreiform movement must be considered (Table 2).

Chorea is hyperkinetic dyskinesia characterized as being involuntary, irregular, unpredictable, small-amplitude, and more distal, whereas ballismus is featured as being large-amplitude, arrhythmic, and more proximal (especially at the shoulder and hip). The ballismus often evolves into chorea. These involuntary movements generally develop while awake, become violent in an emotional mood, and disappear during sleep. Chorea-ballismus can appear in the large majority of patients with diabetic striatopathy (97.7\%) (Chua et al., 2020). The unilateral upper and lower limbs are most frequently affected, but rare bilaterally (only 9.7\%) (Oh et al., 2002; Chua et al., 2020). Also, the facial and tongue muscle can be involved, which could present with eyebrow extrusion, mouth skimming, tongue extension, and other symptoms. The movement disorder usually occurs with severe hyperglycemia simultaneously and is also ameliorated with the recovery of blood glycemic levels. Therefore, the prognosis is generally well after correcting hyperglycemia. In the present case, the patient presented with rare bilateral limb involvements, and after reduction of hyperglycemia, her symptoms were also once relieved.

The laboratory test is essential for screening hyperglycemic status. A previous meta-analysis showed that on the onset day of NKH-CB, the mean serum glycemic level was 481.5 (range, 169-1,264) mg/dl, HbAlc level was $14.4 \%$ (range, 9.9-19.2\%), and serum osmolarity was 305.9 (range, $291-335) \mathrm{mmol} / \mathrm{kg}$ (Oh et al., 2002). Chua et al. (2020) updated the data of average serum glycemic level (414 mg/dl) and HbA1c level (13.1\%).

The features of neuroimaging are the reversible hyperdense and hyperintense lesions limited to the contralateral striatum areas of the affected limbs without edema and mass effect, on CT and T1-weighted sequences magnetic resonance imaging (MRI), respectively (Oh et al., 2002). The radiological findings can be variable signals on T2-weighted, diffusion-weighted imaging, and fluid-attenuation inversion recovery sequences of MRI, and no enhancement on an enhanced scan (Chu et al., 2002; Oh et al., 2002; Zheng et al., 2020). Despite the highly significant correlation between CT and MRI findings, the recent study has shown that there is about one-sixth mismatch and incompatibility between CT and MRI results. MRI is more sensitive than CT in detecting striatal abnormalities associated with diabetic striatopathy (Chua et al., 2020). Additionally, there were a few reported cases with negative findings on both CT and MRI (Chang et al., 2017). Of the three striatal regions, the 
TABLE 2 | Causes of acute/subacute-onset choreiform movement.

\begin{tabular}{|c|c|c|c|c|c|c|}
\hline Causes & Vascular & Metabolic & Infectious & $\begin{array}{l}\text { Immune- } \\
\text { mediated }\end{array}$ & Drug-induced & Others \\
\hline \multirow[t]{5}{*}{ Disorders } & $\begin{array}{l}\text { Ischemic/hemorrhagic } \\
\text { stroke }\end{array}$ & $\begin{array}{l}\text { Hypoglycemia/hyperglycemia } \\
\text { (non-ketotic) }\end{array}$ & Viral encephalitis & $\begin{array}{l}\text { Rheumatologic } \\
\text { diseases (SLE, } \\
\text { APS, SS) }\end{array}$ & $\begin{array}{l}\text { Neuroleptics } \\
\text { Levodopa, } \\
\text { dopamine agonists }\end{array}$ & $\begin{array}{l}\text { Pregnancy } \\
\text { Polycythemia vera }\end{array}$ \\
\hline & $\begin{array}{l}\text { Vascular } \\
\text { malformation }\end{array}$ & $\begin{array}{l}\text { Electrolyte imbalance } \\
\text { (hyponatremia/hypernatremia, } \\
\text { hypercalcemia, } \\
\text { hypomagnesemia) }\end{array}$ & $\begin{array}{l}\text { Group A } \\
\text { beta-hemolytic } \\
\text { streptococcus } \\
\text { (SC) }\end{array}$ & $\begin{array}{l}\text { Autoimmune } \\
\text { neurologic } \\
\text { syndromes/ } \\
\text { paraneoplastic } \\
\text { syndromes }\end{array}$ & $\begin{array}{l}\text { Antiepileptic drugs } \\
\text { (phenytoin, } \\
\text { carbamazepine, } \\
\text { valproic acid) }\end{array}$ & $\begin{array}{l}\text { Tumors } \\
\text { Carbon monoxide } \\
\text { intoxication }\end{array}$ \\
\hline & & $\begin{array}{l}\text { Hyperthyroidism, } \\
\text { hypoparathyroidism/ } \\
\text { hyperparathyroidism }\end{array}$ & $\begin{array}{l}\text { Parasitic } \\
\text { (toxoplasmosis, } \\
\text { cysticercosis) }\end{array}$ & $\begin{array}{l}\text { Demyelinating } \\
\text { disease }\end{array}$ & $\begin{array}{l}\text { Psychostimulants } \\
\text { (cocaine, } \\
\text { amphetamines) }\end{array}$ & Psychogenic chorea \\
\hline & & $\begin{array}{l}\text { Acquired } \\
\text { hepatolenticular } \\
\text { degeneration }\end{array}$ & $\begin{array}{l}\text { Cryptococcal } \\
\text { granuloma } \\
\text { Mycoplasma } \\
\text { Tuberculoma } \\
\text { Neurosyphilis }\end{array}$ & & $\begin{array}{l}\text { Lithium } \\
\text { Oral contraceptives, } \\
\text { estrogen } \\
\text { replacement therapy } \\
\text { Steroids }\end{array}$ & \\
\hline & & & $\begin{array}{l}\text { HIV encephalitis } \\
\text { Prion diseases }\end{array}$ & & $\begin{array}{l}\text { Methotrexate, } \\
\text { cyclosporine } \\
\text { Fluoroquinolones }\end{array}$ & \\
\hline
\end{tabular}

SC, Sydenham's chorea; HIV, human immunodeficiency virus; SLE, systemic lupus erythematosus; APS, antiphospholipid antibody syndrome; SS, Sjögren syndrome.

putamen is the most commonly involved nucleus, and it can be affected isolatedly or in combination with the caudate nucleus and/or globus pallidus (Oh et al., 2002). Similarly, bilateral striatum involvement was uncommon (9.7\%), consistent with bilateral symptoms. Abnormal imaging performances can last for several months, even years after blood glucose correction (Oh et al., 2002).

In the context of association with ICH, NKH-CB could be more easily misdiagnosed as ICH due to the hyperdense on CT imaging initially. The different evolution of lesions between ICH and NKH-CB on a contrasted CT could aid in the differential diagnosis. Perihematoedema, a prominent pathological feature, and corresponding to the hypodense on CT scan that surrounds intracerebral hematomas, can appear in the early-stage acute ICH and its volume starts to increase $1 \mathrm{~h}$ after the onset and grow significantly in the first $24 \mathrm{~h}$ (Wagner et al., 1996; Gebel et al., 2002). Moreover, in the acute stage of ICH, the hematoma's CTattenuation value can rapidly increase to $60-80 \mathrm{HU}$, even to $80-100 \mathrm{HU}$ in the maturation of hematoma, which is generally attributed to the globin (protein) component of the hemoglobin in a hematoma (Brooks et al., 1989; Parizel et al., 2001). However, these developments following hematoma on CT imaging cannot be observed in NKH-CB. In the present case, MRI was not obtained from this patient due to the severe clinical condition, but through analyzing the over-time developments on CT scan, diabetic history, and a series of laboratory results, the diagnosis of $\mathrm{NKH}-\mathrm{CB}$ was finally established. Some histological studies have found that the hyperdense striatal lesions were usually characterized by gliosis, selective neuronal loss, and reactive astrocytes rather than the evidence of hemorrhage or infarction within these areas (Shan et al., 1998; Lee et al., 2002; Cherian et al., 2009). Of course, if conditions permit, MRI remains an
TABLE 3 | Other causes of hyperdense/hyperintense striatal region on CT and T1-weighted MRI.

\begin{tabular}{|c|c|c|}
\hline $\begin{array}{l}\text { Imaging } \\
\text { features }\end{array}$ & Disorder & Regions of involvement \\
\hline \multirow[t]{2}{*}{$\begin{array}{l}\text { Hyperdense on } \\
\text { CT }\end{array}$} & Physiologic calcification & $\begin{array}{l}\text { Bilateral GP, epiphysis, choroid } \\
\text { plexus, habenular nucleus, } \\
\text { cerebral falx }\end{array}$ \\
\hline & $\begin{array}{l}\text { Pathological calcification } \\
\text { (Fahr's disease, } \\
\text { parathyroid dysfunction) }\end{array}$ & $\begin{array}{l}\text { Symmetrically bilateral CN, PN, } \\
\text { GP, thalamus, dentate nuclei, } \\
\text { and subcortical white matter }\end{array}$ \\
\hline \multirow{4}{*}{$\begin{array}{l}\text { Hyperintense on } \\
\text { T1-weighted } \\
\text { MRI }\end{array}$} & Liver disease & $\begin{array}{l}\text { Symmetrically bilateral GP; } \\
\text { Substantia nigra }\end{array}$ \\
\hline & Neurofibromatosis type 1 & Bilateral GP \\
\hline & Carbon monoxide & $\begin{array}{l}\text { Bilateral GP; delayed } \\
\text { leukoencephalopathy }\end{array}$ \\
\hline & Parenteral nutrition & $\begin{array}{l}\text { Symmetrically bilateral GP and } \\
\text { thalamus }\end{array}$ \\
\hline
\end{tabular}

$C T$, computed tomography, MRI, magnetic resonance imaging, GP, globus pallidus, $C N$, caudate nucleus, PN, putamen nucleus.

essential method helpful in not only diagnosis but also judging prognosis (by the value of apparent diffusion coefficient maps) (Chu et al., 2002; Zheng et al., 2020). Selected other causes of hyperdense/hyperintense striatal region on CT or T1-weighted MRI should be also considered for the initial visit (Table 3). Our case is the first entity with two-type hyperdense signs simultaneously, which helps us distinguish NKH-CB from $\mathrm{ICH}$ through the perspective of neuroimaging more intuitively.

Once a diagnosis of $\mathrm{NKH}-\mathrm{CB}$ is established, prompt correction of blood glucose with fluids and insulin and antichorea treatment is recommended. About $26 \%$ of patients can 
reach a benign outcome using glucose-control-only medicine, but additional anti-chorea medications can increase the rate up to $76 \%$ (Chua et al., 2020). The most frequent medication used for chorea treatment is haloperidol with high effectiveness, followed by clonazepam, tetrabenazine, and tiapride (Chua et al., 2020). Besides that, surgical interventions, such as thalamotomy and deep brain stimulation, are also effectively adopted in some refractory cases (Takamatsu et al., 1995; Nakano et al., 2005; Goto et al., 2010). Given the potential adverse side effects of haloperidol, such as metabolic syndrome, dysphoria, and even increased short-term mortality risk of $107 \%$ (especially in the elderly), we did not use this high potent but high-risk regime for our advanced-age critically ill patient (Schneeweiss et al., 2007; Huybrechts et al., 2012; Tyler et al., 2017; Ventriglio et al., 2018). Instead, we chose clonazepam (a benzodiazepine) because clinical evidence supports that antichorea drug is relatively safe (Peiris et al., 1976; Patorno et al., 2017).

Unlike previously reported cases with a favorable prognosis, our case was a critically ill patient accompanied by multiple complications that result in a poor prognosis. The exact pathophysiological mechanism of NKH-CB remains unclear currently, but several hypotheses have been proposed. Given these hypotheses, the interaction of multiple possible mechanisms might explain our case: (1) in a hyperglycemic state, the dysfunction of the striatum could be induced and even aggravated by a series of pathophysiological reactions including anaerobic metabolism of brain cells caused by hypoperfusion and glycometabolism failure, gamma-aminobutyric acid (GABA) depletion of anaerobic metabolism in the striatum due to the non-ketotic state, ischemia of striatal neurons resulting from destroyed blood-brain barrier caused by blood hyperviscosity, and hypersensitivity of dopamine system receptors secondary to the decreased concentration of estrogen in postmenopausal women (Nath et al., 2006; Cheema et al., 2011; Slabu et al., 2011; Tocco et al., 2016). The synergistic effects of imbalanced dopamine and GABA systems and vascular insufficiency may further exacerbate the striatum's dysfunction, which leads to movement disorders (Lin, 2001). (2) In the condition of uncontrolled diabetes, acute ICH could aggravate hyperglycemia by acute stress, metabolic alteration, and autonomic hormonal changes (Xi et al., 2006; Guo et al., 2016). In that situation, hyperglycemia could become uneasy to control due to various secondary responses, such as interference with insulin-mediated glucose uptake induced by increased epinephrine, and insulin resistance (Halter et al., 1984; Tan X. et al., 2014). Moreover, inflammation can markedly enhance insulin resistance, aggravate stress response, and ultimately lead to a deteriorated hyperglycemic state causing rebleeding from a well-controlled hemorrhagic disorder and curing hardly (McAlister et al., 2005; Dungan et al., 2009). Both hyperglycemia and aspiration pneumonia can significantly increase the risks of in-hospital complications and death (Rueda et al., 2010; Mandell and Niederman, 2019). A vicious cycle composed of hyperglycemia, severe infection, and hemorrhagic disease ultimately led to the unfortunate outcome of our case. Of note, in the recurrent hyperglycemic crisis, we did not observe a return of choreaballismus movements for this patient, which might result from the hyperosmolar coma caused by acute deterioration of blood glucose status. In addition, another hyperglycemic crisis could produce a further decrease of cerebral blood flow in the striatal areas, even resulting in the striatal ischemic damage that may interrupt the hyperactivity of the basal ganglia motor circuit (Guisado and Arieff, 1975; Kim et al., 2011).

\section{LIMITATIONS}

Since there was no history of prodromal infections as well as evidence of autoimmune-related diseases, and considering that the infection was caused by aspiration pneumonia, the cerebrospinal fluid (CSF) testing was absent. However, the CSF test can improve the level of diagnostic certainty and be helpful for the exclusion of several other diseases. Moreover, the autopsy pathological study was not available due to the lack of informed consent from her family. The pathological study of the striatum may further specifically explain the nature of the striatal lesions and the pathophysiological mechanism of NKH-CB.

\section{CONCLUSION}

$\mathrm{NKH}-\mathrm{CB}$ is an uncommon metabolic syndrome and generally has a good prognosis. When clinicians are faced with acute or subacute choreiform and ballistic movements, the possibility of NKH-CB should be considered, while serum glucose levels, serum osmolality, and $\mathrm{HbA1c}$ levels should be considered as routine tests. Due to the hyperdense sign on CT imaging, sudden-onset $\mathrm{NKH}-\mathrm{CB}$ can be easily misdiagnosed, particularly in the setting of complicated ICH. In the context of absent MRI, dynamic observation of CT imaging evolutions aids for differential diagnosis, particularly CT-attenuation values. Although the prognosis of most patients with $\mathrm{NKH}-\mathrm{CB}$ is usually good, hemorrhagic disease (ICH and stress-related upper gastrointestinal bleeding) and infection may be risk factors that exacerbate the condition.

\section{DATA AVAILABILITY STATEMENT}

The original contributions presented in the study are included in the article/Supplementary Material, further inquiries can be directed to the corresponding author/s.

\section{ETHICS STATEMENT}

Written informed consent was obtained from the individual(s) for the publication of any potentially identifiable images or data included in this article.

\section{AUTHOR CONTRIBUTIONS}

WT and LT contributed to the conception and design of the manuscript. MD and LZ collected the data and drafted the manuscript. J-YE reviewed and modified the manuscript. All authors contributed to manuscript revision, read, and approved the submitted version. 


\section{FUNDING}

This work was supported by the Major Special Construction Plan about Clinical Medicine of China Medical University in 2018 (Grant Numbers 111-3110118036).

\section{REFERENCES}

Aquino, J. H., Spitz, M., and Pereira, J. S. (2015). Hemichorea-hemiballismus as the first sign of type $1 \mathrm{~b}$ diabetes during adolescence and its recurrence in the setting of infection. J. Child. Neurol. 30, 1362-1365. doi: 10.1177/0883073814553972

Bedwell, S. F. (1960). Some observations on hemiballismus. Neurology 10, 619-622. doi: 10.1212/WNL.10.6.619

Brooks, R. A., Di Chiro, G., and Patronas, N. (1989). MR imaging of cerebral hematomas at different field strengths: theory and applications. J. Comput. Assist. Tomogr. 13, 194-206. doi: 10.1097/00004728-198903000-00002

Chang, X., Hong, W., Yu, H., and Yao, Y. (2017). Chorea associated with nonketotic hyperglycemia: a case report with atypical imaging changes. Medicine 96:e8602. doi: 10.1097/MD.0000000000008602

Cheema, H., Federman, D., and Kam, A. (2011). Hemichorea-hemiballismus in non-ketotic hyperglycaemia. J. Clin. Neurosci. 18, 293-294. doi: 10.1016/j.jocn.2010.04.036

Cherian, A., Thomas, B., Baheti, N. N., Chemmanam, T., and Kesavadas, C. (2009). Concepts and controversies in nonketotic hyperglycemia-induced hemichorea: further evidence from susceptibility-weighted MR imaging. J. Magn. Reson. Imaging 29, 699-703. doi: 10.1002/jmri.21672

Chu, K., Kang, D. W., Kim, D. E., Park, S. H., and Roh, J. K. (2002). Diffusionweighted and gradient echo magnetic resonance findings of hemichoreahemiballismus associated with diabetic hyperglycemia: a hyperviscosity syndrome? Arch. Neurol. 59, 448-452. doi: 10.1001/archneur.59.3.448

Chua, C. B., Sun, C. K., Hsu, C. W., Tai, Y. C., Liang, C. Y., and Tsai, I. T. (2020). "Diabetic striatopathy": clinical presentations, controversy, pathogenesis, treatments, and outcomes. Sci. Rep. 10:1594. doi: 10.1038/s41598-020-58555-w

Dungan, K. M., Braithwaite, S. S., and Preiser, J. C. (2009). Stress hyperglycaemia. Lancet 373, 1798-1807. doi: 10.1016/S0140-6736(09)60553-5

Faundez, T., Klee, P., Hanquinet, S., Schwitzgebel, V., Burkhard, P. R., and Korff, C. M. (2016). Diabetic striatopathy in childhood: a case report. Pediatrics 137:e20143761. doi: 10.1542/peds.2014-3761

Gebel, J. J., Jauch, E. C., Brott, T. G., Khoury, J., Sauerbeck, L., Salisbury, S., et al. (2002). Natural history of perihematomal edema in patients with hyperacute spontaneous intracerebral hemorrhage. Stroke 33, 2631-2635. doi: 10.1161/01.STR.0000035284.12699.84

Goto, T., Hashimoto, T., Hirayama, S., and Kitazawa, K. (2010). Pallidal neuronal activity in diabetic hemichorea-hemiballism. Mov. Disord. 25, 1295-1297. doi: $10.1002 / \mathrm{mds} .23058$

Guisado, R., and Arieff, A. I. (1975). Neurologic manifestations of diabetic comas: correlation with biochemical alterations in the brain. Metabolism 24, 665-679. doi: 10.1016/0026-0495(75)90146-8

Guo, X., Li, H., Zhang, Z., Li, S., Zhang, L., Zhang, J., et al. (2016). Hyperglycemia and mortality risk in patients with primary intracerebral hemorrhage: a metaanalysis. Mol. Neurobiol. 53, 2269-2275. doi: 10.1007/s12035-015-9184-4

Halter, J. B., Beard, J. C., and Porte, D. J. (1984). Islet function and stress hyperglycemia: plasma glucose and epinephrine interaction. Am. J. Physiol. 247, E47-E52. doi: 10.1152/ajpendo.1984.247.1.E47

Huybrechts, K. F., Gerhard, T., Crystal, S., Olfson, M., Avorn, J., Levin, R., et al. (2012). Differential risk of death in older residents in nursing homes prescribed specific antipsychotic drugs: population based cohort study. BMJ 344:e977. doi: 10.1136/bmj.e977

Kim, Y. D., Cho, H. J., Song, I. U., and Chung, S. W. (2011). Complete disappearance of hemichorea-hemiballism due to hyperglycemia following acute ischemic stroke. Eur. Neurol. 66, 339-342. doi: 10.1159/000333285

Lee, E. J., Choi, J. Y., Lee, S. H., Song, S. Y., and Lee, Y. S. (2002). Hemichoreahemiballism in primary diabetic patients: MR correlation. J. Comput. Assist. Tomogr. 26, 905-911. doi: 10.1097/00004728-200211000-00009

\section{SUPPLEMENTARY MATERIAL}

The Supplementary Material for this article can be found online at: https://www.frontiersin.org/articles/10.3389/fnins. 2021.690761/full\#supplementary-material

Lin, J. J. (2001). Ipsilateral putamen hyperintensity on T1-weighted MRI in non-ketotic hyperglycemia with hemiballism-hemichorea: a case report. Parkinsonism Relat. Disord. 7, 319-321. doi: 10.1016/S1353-8020(00)00072-9

Mandell, L. A., and Niederman, M. S. (2019). Aspiration pneumonia. N. Engl. J. Med. 380, 651-663. doi: 10.1056/NEJMra1714562

McAlister, F. A., Majumdar, S. R., Blitz, S., Rowe, B. H., Romney, J., and Marrie, T. J. (2005). The relation between hyperglycemia and outcomes in 2,471 patients admitted to the hospital with community-acquired pneumonia. Diabetes Care 28, 810-815. doi: $10.2337 /$ diacare.28.4.810

Nakano, N., Uchiyama, T., Okuda, T., Kitano, M., and Taneda, M. (2005). Successful long-term deep brain stimulation for hemichorea-hemiballism in a patient with diabetes. Case report. J. Neurosurg. 102, 1137-1141. doi: 10.3171/jns.2005.102.6.1137

Nath, J., Jambhekar, K., Rao, C., and Armitano, E. (2006). Radiological and pathological changes in hemiballism-hemichorea with striatal hyperintensity. J. Magn. Reson. Imaging 23, 564-568. doi: 10.1002/jmri.20548

Oh, S. H., Lee, K. Y., Im, J. H., and Lee, M. S. (2002). Chorea associated with nonketotic hyperglycemia and hyperintensity basal ganglia lesion on T1-weighted brain MRI study: a meta-analysis of 53 cases including four present cases. J. Neurol. Sci. 200, 57-62. doi: 10.1016/S0022-510X(02)00133-8

Ondo, W. G. (2011). Hyperglycemic nonketotic states and other metabolic imbalances. Handb. Clin. Neurol. 100, 287-291. doi: 10.1016/B978-0-444-52014-2.00021-5

Parizel, P. M., Makkat, S., Van Miert, E., Van Goethem, J. W., van den Hauwe, L., and De Schepper, A. M. (2001). Intracranial hemorrhage: principles of CT and MRI interpretation. Eur. Radiol. 11, 1770-1783. doi: 10.1007/s003300000800

Patorno, E., Glynn, R. J., Levin, R., Lee, M. P., and Huybrechts, K. F. (2017). Benzodiazepines and risk of all cause mortality in adults: cohort study. BMJ 358:j2941. doi: 10.1136/bmj.j2941

Peiris, J. B., Boralessa, H., and Lionel, N. D. (1976). Clonazepam in the treatment of choreiform activity. Med. J. Aust. 1, 225-227. doi: 10.5694/j.1326-5377.1976.tb140550.x

Rueda, A. M., Ormond, M., Gore, M., Matloobi, M., Giordano, T. P., and Musher, D. M. (2010). Hyperglycemia in diabetics and non-diabetics: effect on the risk for and severity of pneumococcal pneumonia. J. Infect. 60, 99-105. doi: 10.1016/j.jinf.2009.12.003

Ryan, C., Ahlskog, J. E., and Savica, R. (2018). Hyperglycemic chorea/ballism ascertained over 15 years at a referral medical center. Parkinsonism Relat. Disord. 48, 97-100. doi: 10.1016/j.parkreldis.2017.12.032

Schneeweiss, S., Setoguchi, S., Brookhart, A., Dormuth, C., and Wang, P. S. (2007). Risk of death associated with the use of conventional versus atypical antipsychotic drugs among elderly patients. CMAJ 176, 627-632. doi: 10.1503/cmaj.061250

Shan, D. E., Ho, D. M., Chang, C., Pan, H. C., and Teng, M. M. (1998). Hemichorea-hemiballism: an explanation for MR signal changes. AJNR Am. J. Neuroradiol. 19, 863-870.

Slabu, H., Savedia-Cayabyab, S., Senior, P., and Arnason, T. (2011). Permanent haemichorea associated with transient hyperglycemia. BMJ Case Rep. 2011:bcr0820114641. doi: 10.1136/bcr.08.2011.4641

Takamatsu, K., Ohta, T., Sato, S., Sano, A., Takahashi, K., Murakami, Y., et al. (1995). Two diabetics with hemichorea-hemiballism and striatal lesions. No To Shinkei 47, 167-172.

Tan, X., He, J., Li, L., Yang, G., Liu, H., Tang, S., et al. (2014). Early hyperglycaemia and the early-term death in patients with spontaneous intracerebral haemorrhage: a meta-analysis. Intern. Med. J. 44, 254-260. doi: 10.1111/imj.12352

Tan, Y., Xin, X., Xiao, Q., Chen, S., Cao, L., and Tang, H. (2014). Hemiballism-hemichorea induced by ketotic hyperglycemia: case report 
with PET study and review of the literature. Transl. Neurodegener. 3:14. doi: 10.1186/2047-9158-3-14

Tocco, P., Barbieri, F., Bonetti, B., Barillari, M., Marangi, A., and Tinazzi, M. (2016). Hemichorea-hemiballismus in patients with non-ketotic hyperglycemia. Neurol. Sci. 37, 297-298. doi: 10.1007/s10072-015-2408-6

Tyler, M. W., Zaldivar-Diez, J., and Haggarty, S. J. (2017). Classics in chemical neuroscience: haloperidol. ACS Chem. Neurosci. 8, 444-453. doi: 10.1021/acschemneuro.7b00018

Ventriglio, A., Baldessarini, R. J., Vitrani, G., Bonfitto, I., Cecere, A. C., Rinaldi, A., et al. (2018). Metabolic syndrome in psychotic disorder patients treated with oral and long-acting injected antipsychotics. Front. Psychiatry 9:744. doi: 10.3389/fpsyt.2018.00744

Wagner, K. R., Xi, G., Hua, Y., Kleinholz, M., de Courten-Myers, G. M., Myers, R. E., et al. (1996). Lobar intracerebral hemorrhage model in pigs: rapid edema development in perihematomal white matter. Stroke 27, 490-497. doi: 10.1161/01.STR.27.3.490

Wintermark, M., Fischbein, N. J., Mukherjee, P., Yuh, E. L., and Dillon, W. P. (2004). Unilateral putaminal CT, MR, and diffusion abnormalities secondary to nonketotic hyperglycemia in the setting of acute neurologic symptoms mimicking stroke. AJNR Am. J. Neuroradiol. 25, 975-976.
Xi, G., Keep, R. F., and Hoff, J. T. (2006). Mechanisms of brain injury after intracerebral haemorrhage. Lancet Neurol. 5, 53-63. doi: 10.1016/S1474-4422(05)70283-0

Xiao, F., Liu, M., and Wang, X. F. (2019). Involuntary choreiform movements in a diabetic patient. Lancet 393:1033. doi: 10.1016/S0140-6736(19)30304-6

Zheng, W., Chen, L., Chen, J. H., Lin, X., Tang, Y., Lin, X. J., et al. (2020). Hemichorea associated with non-ketotic hyperglycemia: a case report and literature review. Front. Neurol. 11:96. doi: 10.3389/fneur.2020.00096

Conflict of Interest: The authors declare that the research was conducted in the absence of any commercial or financial relationships that could be construed as a potential conflict of interest.

Copyright (C) 2021 Dong, E, Zhang, Teng and Tian. This is an open-access article distributed under the terms of the Creative Commons Attribution License (CC BY). The use, distribution or reproduction in other forums is permitted, provided the original author(s) and the copyright owner(s) are credited and that the original publication in this journal is cited, in accordance with accepted academic practice. No use, distribution or reproduction is permitted which does not comply with these terms. 